


\section{Análisis del confort térmico en los proyectos participantes de la Universidad de Boyacá} en Convive VI ${ }^{1}$ Thermal Comfort Analysis of the University of Boyacá's projects participating in Convive VI

\section{Resumen:}

\section{Palabras clave:}

Confort Térmico, Software de Evaluación Energética, Diseño Solar Pasivo.

Key words:

Thermal Comfort, Software of Energetic Evaluation, Passive Solar Design.

Recibido: 10 -jul- 2013 Aceptado: 19-sep- 2013

\footnotetext{
* Arquitecta del Instituto Superior Técnico, en Lisboa (Portugal). Realizó la práctica profesional en la Facultad de Arquitectura y Bellas Artes de la Universidad de Boyacá, en el segundo semestre de 2011
}

\footnotetext{
${ }^{1}$ ConvivE VI: Concurso internacional de Arquitectura, en esta versión se tituló: "Comunidades indígenas, Economía Post-Minera y Urbanismo Sostenible: Uribia 2050"
}

Este es un artículo de reflexión derivado de investigación que, en primer lugar, analiza algunos programas de simulación de confort térmico, para luego explicar su aplicabilidad a proyectos especíicicos, en este caso los que se presentaron por parte de la Universidad de Boyacá al concurso internacional de arquitectura ConvivE VI. En este concurso, uno de los aspectos relevantes por resolver es el problema del hábitat, especialmente de la vivienda social, aunque también se otorga gran importancia al tema de la sostenibilidad en los edificios. El documento tiene como objetivo mostrar -luego de una investigación teórica- el seguimiento realizado a dichos proyectos, las recomendaciones y los cambios efectuados luego de los análisis finales, referidos específicamente al confort térmico de las viviendas planteadas para participar en ConvivE VI. Por la naturaleza del lugar de emplazamiento, dichas viviendas fueron diseñadas con materiales locales, sin técnicas complejas de construcción e incorporando algunos métodos de diseño solar pasivo que según el estudio realizado, en un principio no eran confortables térmicamente. Sin embargo, después de atender las sugerencias realizadas y las especificaciones de materiales surgidas tras la simulación en el programa seleccionado, se consiguió llegar a las temperaturas de confort que se requerían, teniendo en cuenta el clima de Uribía, región donde se proyectaron las viviendas.

\section{Abstract}

This is an article of reflection derived from research. Firstly, a theoretical background is considered and some simulation programs of thermal comfort are analyzed, in order to explain their applicability to specific projects, in this case those presented by the Universidad de Boyacá to the international architecture contest ConvivE VI. In this contest one significant issue to be resolved is the problem of habitat, especially regarding social housing, although the topic of sustainability in buildings possesses noticeable importance as well. The paper aims to show the evaluation of the projects, the recommendations and changes adopted following the final analyses, which were specifically related to the thermal comfort of the dwellings participating in ConvivE VI. Due to the nature of the installation site these houses were designed with local materials, omitting complex construction techniques and incorporating some methods of passive solar design, not thermally comfortable according to the study carried out. However, after attending suggestions and specifications related to the materials, which were formulated by conducting simulations in the selected program, the required temperatures of comfort were gotten, taking into account the climate of Uribía (where the dwellings were projected). 
Este artículo surge como parte del trabajo de tesis realizado por la autora, titulado Herramientas de simulación ambiental y energética para la práctica de un proyecto de Arquitectura - Un análisis crítico? El interés para el desarrollo del tema fue, inicialmente, la intención de crear un programa de simulación energética y ambiental que actuase directamente en el soltware de modelación Auto $C A D \Theta_{\text {; }}$ sin embargo, el proyecto inicial sufrió modificaciones y se empezó con la comprensión de los conceptos subyacentes a los programas de simulación energética, por lo que se decidió analizar de forma crítica y desde la perspectiva del arquitecto, el software disponible en la actualidad para este tipo de análisis. Así, en la disertación de la tesis antes mencionada, se pretendió

\section{INTRODUCCIÓN}

${ }^{2}$ Proyecto de tesis desarrollado en el Instituto Superior Técnico en Lisboa (Portugal). comprender cuál es el software más accesible para un arquitecto a partir del examen de las características de los diferentes programas en la perspectiva de dicho profesional. Se consideraron aspectos como los 'outputs', la facilidad de utilización, el rigor de los resultados y su adecuación a diferentes finalidades.

Después de una investigación teórica sobre los conceptos subyacentes a los programas, la descripción de estos últimos y la revisión bibliográfica que permitió efectuar

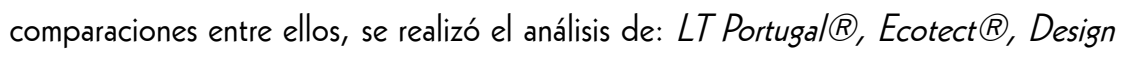

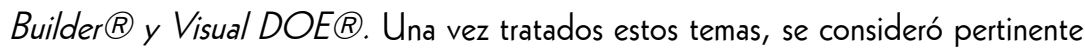
realizar una aplicación práctica en un proyecto específico durante la pasantía de la autora en la Universidad de Boyacá, de manera que una vez consolidada la base conceptual de la tesis, como parte de las actividades de la práctica profesional 
por la Universidad de Boyacá. Finalmente se exponen los análisis realizados a dichos proyectos, las sugerencias planteadas y la mejoría en términos constructivos y de confort térmico luego de las recomendaciones proporcionadas. Se finaliza con las conclusiones, entre ellas dos que es pertinente destacar: la evaluación de proyectos mediante simulación es una herramienta valiosa para proyectar edificios confortables térmicamente; y para garantizar principios de sostenibilidad es necesario tener en cuenta elementos tan sencillos como la orientación, la ubicación de vanos y llenos, los criterios de asoleación y el uso de materiales locales y poco contaminantes.

desarrollada en dicha institución, la investigadora apoyó a tres grupos participantes en el concurso ConvivE $\mathrm{VI}$, dinámica que es descrita más adelante.

En este texto se pretende demostrar el mejoramiento de los proyectos presentados al concurso por los estudiantes, en frentes relacionados con el confort térmico y las soluciones sostenibles, a través de simulaciones en el programa escogido. La exposición se estructura en tres partes. La primera abarca el estado del arte en materia de programas de simulación ambiental y energética, al tiempo que se consideran las principales características de estos. Posteriormente, se abordan los conceptos inherentes al confort térmico y se describe tanto el concurso ConvivE $\mathrm{VI}$ como los proyectos presentados

\section{METODOLOGÍA}

En el desarrollo del trabajo se plantearon dos fases. Una de ellas fue teórica y comprendió el análisis e investigación sobre los materiales poco usuales -y sus características- usados en los proyectos. De igual modo, se reunieron datos climáticos de la región donde se ubicaron los proyectos, para su posterior utilización en los programas de simulación energética y ambiental, y se consideraron soluciones solares pasivas factibles de ser aplicadas. Por su parte, la fase práctica consistió en el apoyo al desarrollo de los proyectos presentados al concurso. En esta etapa se propusieron cambios constructivos y se evaluaron las propuestas con el programa de simulación ambiental y energética para posteriormente hacer recomendaciones, en aras de mejorar lo planteado.

\section{PROGRAMAS DE SIMULACIÓN AMBIENTAL Y ENERGÉTICA}

\section{En disciplinas como la arquitectura, existe una necesidad cada vez} mayor de emplear software para realizar análisis expeditos de variables esenciales (componente ambiental, confort, luz, desempeños en sustentabilidad y costos, entre otras) que hechos de otra forma serían lentos y poco precisos. De tal manera, es casi obligatoria la utilización de algún soporte de software, pero si este no corresponde con las necesidades del usuario, será poco útil para la tarea a desempeñar. Así, los estudios en esta dirección permiten saber cuál es el programa más adecuado, lo cual posibilita mayor rapidez y precisión en el procesamiento y la interpretación de los resultados obtenidos. 
Actualmente se cuenta con estudios en este campo, es decir, en la comparación de software de simulación ambiental y energética. Por ejemplo, Evan Mills, (2004), compara 65 programas de análisis energético, mientras que Crawley y sus asociados (2005) lo hacen sobre 22 programas. Estos autores efectúan un examen detallado de las características intrínsecas de cada programa. El Departamento de Energía de los Estados Unidos, en el Directorio de Software de Energía para Edificios (U.S. Department of Energy, 2011), tiene especificados varios de los paquetes existentes actualmente en el mercado. Por medio de descripciones se revelan sus puntos frágiles y fuertes, de tal suerte que a pesar de su escasa profundidad, dicho estudio hace un importante muestreo general del tema de estudio. Pero ninguno de los tres trabajos referidos tuvo en cuenta al arquitecto como usuario principal y final del software ${ }^{3}$.

A su vez, para la evaluación ambiental y energética de un edificio se realizó un análisis preliminar del software existente en el mercado. Fueron considerados programas como Autodesk $\AA$ Ecotect ${ }^{\circledR}$ Analysis, LT-Portugal $(\AA$, Design Builder $\AA$

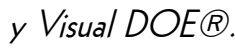

${ }^{3}$ Por lo tanto, la disertación de la tesis mencionada anteriormente se vislumbra como un estudio de gran utilidad tanto para los profesores como para los arquitectos, en el sentido de que no se reduce a una comparación exhaustiva sino que introduce una orientación específica para la práctica del arquitecto.

${ }^{4}$ Por ejemplo en las clases de Diseño Ambiental I y II, que hacen parte del Máster en Arquitectura del Instituto Superior Técnico.
El Autodesk ${ }^{\circ}$ Ecotect ${ }^{\circledR}$ Analysis es muy utilizado en varias facultades de arquitectura ${ }^{4}$. Este simulador es una solución de análisis de diseño sustentable con herramientas de trabajo direccionadas para el arquitecto, las cuales ayudan a cuantificar el impacto de los factores ambientales sobre un edificio. Este software facilita la conducción de las simulaciones y la visualización de los resultados, es decir, su interacción e interpretación. Permite, además, tomar decisiones más sustentables durante la etapa embrionaria del proyecto, para mejorar el desempeño ambiental del edificio y lograr menores costos totales. A través de la modelación en Revit ${ }^{\circledR}$ (formato sbXML), es posible importar los ficheros 3D sin necesidad de remodelar el proyecto en el Ecotect ${ }^{\circledR}$, lo que evidencia una de las fallas con relación al Auto $C A D \otimes$ (formato DXF), manejado por gran parte de los usuarios. 


\section{El Autodesk ${ }^{\circledR}$ Ecotect ${ }^{\circledR}$ Analysis} incluye una variedad de análisis, de tal modo que puede considerarse satisfactoriamente completo. Suele ser empleado en situaciones corrientes cuando no es necesaria la profundización de algún parámetro más específico y entre sus principales áreas de estudio se cuentan: ventilación natural, desempeño térmico, radiación solar, impacto visual, sombreado, factor luz-día e iluminación y análisis acústico.

\section{El LT-Portugal $\otimes$ es un programa de} diseño energético que determina de forma rápida el uso de energía del edificio, la luz, el enfriamiento, la ventilación, la calefacción y las implicaciones del confort térmico. Es una variante del método LT, pues aplica la reglamentación portuguesa (RCCTE). Su uso es sencillo, sus outputs son de fácil interpretación y resulta aplicable a una gran diversidad de situaciones. Presenta gráficos, tablas y casos de comparación, lo que permite una optimización de las soluciones escogidas.

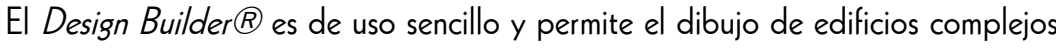
por parte de usuarios con menos experiencia, pues utiliza una simulación energética dinámica avanzada cuya base es el Energy Plus ${ }^{\circledR}$. Ofrece datos del comportamiento físico y ambiental del edificio, una simulación detallada y una visualización inmediata y real. Sin embargo, en la importación de ficheros 3D, se observa el mismo problema

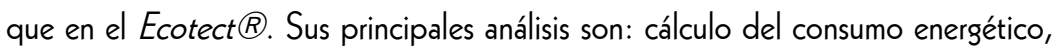
evaluación de opciones de fachadas para recalentamiento y apariencia visual, simulación térmica en edificios ventilados naturalmente, factor luz-día e iluminación, sombreado y cálculo de equipamientos de calefacción y enfriamiento.

\section{El Visual $D O E \circledast$ es una interfaz gráfica del $D O E-2.1 E \AA$, el cual es un} software de simulación energética de edificios. Es más robusto y menos intuitivo que los anteriores, además, su manejo es menos evidente y en esencia usa un lensuaje de programación o BDL, aplicado a un editor de texto. Con el Visual $D O E \circledast$ los usuarios pueden construir modelos geométricos de edificios a través de la interfaz gráfica y tienen la opción de importar ficheros DXF. Es especialmente útil para estudios de dibujos alternativos de sistemas de AVAC y también es posible utilizarlo para sistemas de iluminación y calentamiento de agua. Los outputs son informes, sumarios y gráficos relacionados con el consumo de gas y electricidad, como también con el costo de dicho uso, que pueden ser exportados directamente del programa. Su manejo es sencillo para usuarios familiarizados con los sistemas de edificios. 


\section{ANÁLISIS DE LOS}

\section{PROGRAMAS - DISEÑO}

\section{SOLAR PASIVO Y CONFORT}

\section{TÉRMICO}

\section{Todos los programas descritos poseen conceptos subyacentes relacionados con el confort}

térmico. Estos conceptos, a su vez, están íntimamente ligados con las so-
Para saber cuál es el nivel de confort térmico, los programas efectúan análisis térmicos de los proyectos y ofrecen resultados de los mismos. En este artículo solo se explora el Autodesk $®$ Ecotect $\Theta$ Analysis, pues se trata del software que la autora maneja con mayor experiencia. Todos los conceptos y análisis descritos pertenecen a este programa, pero son similares a los utilizados por otros. Los principales conceptos presentados son tomados, en su mayoría, de Natural Frequency (2011), website de ayuda sobre el programa Autodesk $\AA$ Ecotect $\Theta$ Analysis que contiene conceptos, tutoriales y cursos, como también de la guía de sostenibilidad de Zimmerman (2003).

\section{Diseño Solar Pasivo}

El concepto de diseño solar pasivo es muy antiguo y se define por la utilización de la energía que viene de la naturaleza (como el sol y el viento) para que la energía convencional proveniente de los combustibles fósiles no sea tan requerida, lo cual conlleva a espacios confortables térmicamente. Este diseño se relaciona directamente con la sostenibilidad, pues a través de simples modificaciones en un proyecto es posible omitir los sistemas activos de calentamiento y enfriamiento, de tal suerte que el consumo energético de un edificio, y por ende su impacto ambiental, es mucho menor. Asimismo, la manutención de una edificación se torna más fácil, menos costosa y reviste un menor gasto de energía. Entre los principales elementos que se consideran en este tipo de diseño se encuentran: orientación y ubicación, forma del edificio, distribución de espacios, masa térmica, aislamiento y ventilación. A continuación se hace mención a cada uno de ellos.

\section{Confort humano}

Para saber cuál es el confort térmico de un edificio, primero debe tenerse en cuenta el confort humano. Este confort es muy variable, pues depende de cada persona y de las sensaciones que se tienen con determinados factores, como las temperaturas, el tipo de vestimenta, la localización y la hora del día. Según la Natural Frequency (2011), los factores ambientales más relevantes que afectan el confort humano son: la temperatura ambiente del aire, la temperatura media radiante de los objetos 
envolventes, la humedad relativa y el movimiento del aire. En cuanto a factores fisiológicos, pueden mencionarse el metabolismo y el nivel de ropas. Por lo tanto, es muy difícil determinar con certeza el confort exacto de un ser humano dentro de un edificio, pues son varios los factores que lo influencian. Usualmente, para lograr un acercamiento al confort se intenta que haya un compromiso entre el usuario y el arquitecto encargado de proyectar. Así por ejemplo, el usuario se compromete a usar ropas adecuadas en cada estación y el arquitecto se compromete a proyectar un edificio que esté dentro de la temperatura de confort (normalmente entre los 18 y $\left.26^{\circ} \mathrm{C}\right)$, sin ningún sistema de calentamiento o enfriamiento.

\section{Orientación y ubicación}

Uno de los principales elementos que se deben tener en cuenta para el diseño de un proyecto es la orientación, pues de acuerdo con esta condición, un edificio puede recibir más o menos radiación solar, la cual ayuda a controlar su confort térmico y lumínico. Por lo tanto, es necesario que el edificio cuente con bastante radiación solar durante el invierno para aumentar su temperatura interna, y que no reciba tanta durante el verano para que sus espacios no se calienten demasiado. La orientación depende mucho de la localización del proyecto, pues el movimiento del sol es diferente en las distintas áreas del planeta. La ubicación también reviste relevancia, pues las condiciones en este sentido determinan todo el desarrollo posterior. A su vez, con el fin de filtrar la incidencia solar directamente en el edificio, lo recomendable es utilizar los árboles ya existentes en el sitio.

\section{Forma del edificio}

Es importante que la forma sea bastante simple, en aras de minimizar pérdidas y ganancias de calor y optimizar la utilización de materiales. Los edificios con muchas esquinas aumentan drásticamente esos factores. Una buena decisión, en lo posible, consiste en desarrollar edificios rectangulares, con las fachadas más grandes orientadas al sur y al norte, en vez de formas cuadradas que eventualmente tengan la misma cantidad de ventanas tanto en el este y el oeste como en el norte y el sur.

\section{Distribución de los espacios}

En lo relativo a la distribución espacial interior, se deben tener en cuenta varios factores: localización de baños, circulaciones, sistemas de calefacción y enfriamiento y depósitos. En edificios de oficinas de múltiples pisos, los factores anotados anteriormente deben estar preferencialmente en el interior (como el centro del edificio). En edificios de habitación, es preferencial que los espacios no utilizados a diario por las personas se ubiquen en el lado con menos ventajas de iluminación, de manera que los espacios ocupados con mayor frecuencia vividos por las personas, tengan una orientación óptima. 
de estar bien localizadas para una adecuada ventilación cruzada interna. En cuanto a materiales, es preferible utilizar aquellos locales, de fácil manutención, durables, reciclables, renovables y que no sean tóxicos.

\section{Diseño del Edificio}

Para un buen funcionamiento del edificio, tanto energético como de confort, es necesario considerar ciertos requerimientos cuando se diseña. Por ejemplo, el porcentaje de aperturas y ventanas debe ser maximizado en las fachadas norte y sur, y minimizado en las fachadas este y oeste, con el fin de aprovechar de la mejor manera la radiación solar tanto en el invierno como en el verano (en el caso de los países del hemisferio norte que tienen estaciones). Igualmente, es conveniente disponer de buenas sombras proyectadas en, por ejemplo, las fachadas sur, este y oeste a través de la cubierta, para impedir que el sol entre directamente en el interior, $y$ caliente demasiado. Las aperturas han

Otros factores a tener en cuenta cuando se empieza a diseñar son la masa térmica, el aislamiento térmico y la ventilación. La masa térmica se caracteriza por la capacidad del material de almacenar calor, lo que permite estabilizar las temperaturas interiores, aumenta el tiempo empleado por el calor para pasar del exterior hacia el interior de los espacios y confiere una notable diferencia entre la temperatura exterior y la interior. Los materiales con gran masa térmica son los concretos, la tierra, el adobe, los ladrillos y la piedra, entre otros.

El aislamiento térmico es fundamental dentro del diseño, pues posibilita que las diferencias entre las temperaturas del exterior y del interior sean mayores, lo cual mejora el confort térmico. Además, esto se traduce en un ahorro de considerables cantidades de energía, pues en principio no es necesario calentar o enfriar el edificio con temperaturas extremas en el exterior. Pero aunque se requiera calentar o enfriar, es posible usar sistemas de bajo consumo que no empleen mucha energía. Por último, la ventilación es crucial para un buen confort térmico, no solo en países con estaciones. Se debe hacer un estudio de vientos del lugar para después ubicar puertas y ventanas con eficiencia, de tal modo que se aproveche la dirección de los vientos y se obtenga una satisfactoria ventilación durante la época de calor. Adicionalmente, por medio de una correcta ventilación las concentraciones de dióxido de carbono y de vapor se minimizan, al tiempo que se reduce el surgimiento de hongos. 
Análisis térmico

El programa Autodesk $\AA$ Ecotect $(\mathbb{A}$

Analysis efectúa varias evaluaciones a los edificios, tanto en el aspecto térmico como en el energético. A través de la interpretación de los resultados de estas evaluaciones, es factible determinar si un edificio es sostenible y confortable en términos térmicos, o si no lo es. $A$ continuación se describen algunos de dichos análisis y los conceptos necesarios para entender mejor el programa.

\section{Datos Climáticos}

Para iniciar cualquier análisis, es necesario tener un fichero de datos climáticos del sitio donde se ubica el proyecto. Esos datos influyen en todos los análisis, pues mediante estos ficheros se obtienen las coordenadas, las temperaturas del aire, las direcciones del viento y su velocidad, el movimiento del sol, la humedad relativa, la radiación solar y la cantidad de lluvia que cae durante el año. Esta información conlleva a evaluaciones más precisas y reales.
Algunas veces es difícil obtener estos ficheros de datos climáticos porque no hay estaciones meteorológicas cerca de los lugares donde se realizan los proyectos, o cuando las hay, tienen la información en formato digital o en ficheros que los

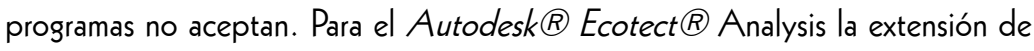
esta clase de datos climáticos es. Wea.

\section{Análisis de Confort térmico}

La mejor manera de constatar si el edificio es confortable o no desde el punto de vista térmico, es con el análisis de confort térmico, proceso que se requiere la realización de varias acciones en el programa. La primera de ellas es escoger el fichero de datos climáticos del sitio del proyecto. Después, al modelar el edificio, se hace corresponder una zona a cada espacio. Si la modelación ya fue realizada en otro programa como el Auto $C A D \otimes$ o el $\operatorname{Archi} C A D \otimes$, se importa un fichero tipo DXF y a partir de éste, se modelan las diferentes zonas. Desafortunadamente no se puede utilizar el 3D disponible en los otros programas, pues cuando la información es importada, todos los elementos se transforman en líneas, condición que dificulta la modelación 3D por zonas. Una vez que cada una de estas ha sido modelada, se atribuyen los materiales para los distintos elementos (paredes, puertas, ventanas, cubiertas). Asimismo, se asignan otras características para cada zona, tales como el nivel de ropas que las personas probablemente utilizarán, el porcentaje de humedad dentro del espacio, la velocidad del aire, el número de individuos, las actividades previstas, la temperatura de confort que se considera, el tipo de sistema (calentamiento o enfriamiento) implementado, y la duración de este sistema, entre otros. Por último, se escogen las redes de análisis, es decir, los espacios a evaluar. Cuando todos estos factores están de acuerdo con el proyecto, se procede con el análisis de confort térmico. Como parte de este se obtienen dos gráficos, uno más llamativo e interactivo con el usuario, gracias al cual es posible verificar las temperaturas interiores de los espacios a una cierta hora, de una determinada fecha, como se representa en la figura 1. El otro gráfico, más sencillo, representa las temperaturas durante todo el día de una fecha en particular, como se observa en la figura 2. 


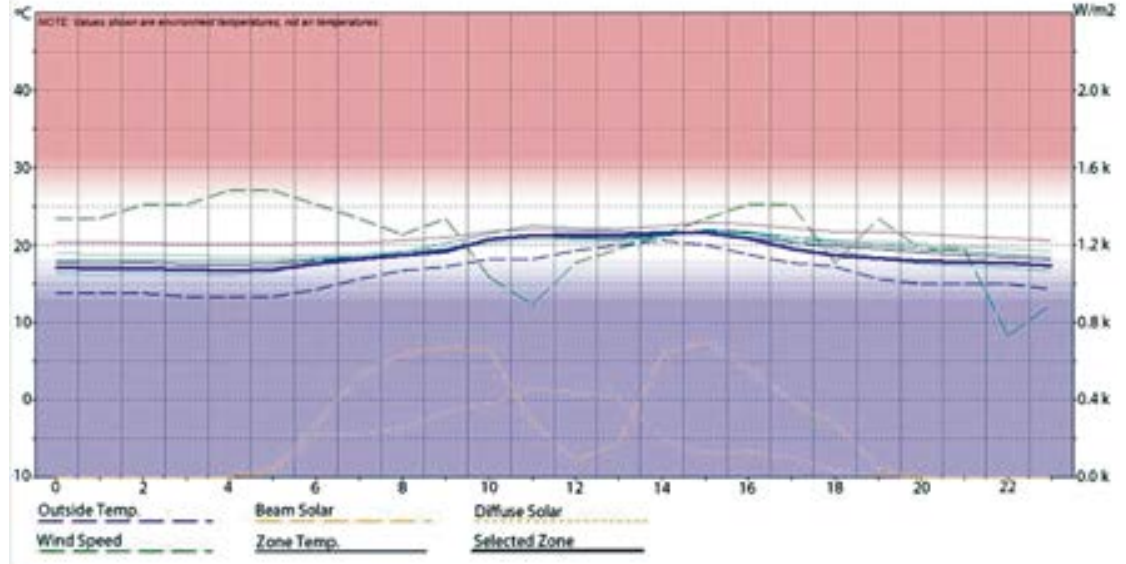

Figura 2. Análisis de las temperaturas a lo largo del día en el programa Autodesk Ecotect Analysis ${ }^{\circledR}$, para el 28 de mayo de 2013, en Lisboa Fuente: autora

El primer gráfico muestra, en la red de análisis, las temperaturas en cada espacio. Igualmente, para una fácil interpretación, presenta una escala de los colores que aparecen en la red. En el segundo gráfico se observan las horas en el eje $X$, mientras que en el $Y$, las temperaturas. También se aprecian las temperaturas exteriores, las incidencias solares y la velocidad del viento, características representadas a lo largo del día. A su vez, al seleccionar una zona específica se reconocen las temperaturas de confort: de azul las que se encuentran por debajo del confort, y en rojo, aquellas por encima. El intervalo de temperaturas de confort está representado por el blanco, y en esta banda se espera que las zonas del proyecto estén desarrolladas.

Cuando se interpretan estos gráficos pueden verse las alteraciones en el desarrollo de las temperaturas, a través de variaciones del viento o de la luz solar que incide en las fachadas. Así, es posible hacer modificaciones en los espacios en lo relacionado con aperturas, materiales, orientación y sombreado, entre otros elementos, conforme se desarrollan las temperaturas. 
La única desventaja de este software es que no indica los cambios factibles de ser aplicados para mejorar el confort térmico. Simplemente, analiza todo cuanto se modela y caracteriza, por lo que el usuario debe interpretar los resultados y decidir las modificaciones necesarias. Así, al usuario le corresponde manejar conceptos de diseño solar pasivo para mejorar el diseño de sus edificios.

\section{CONVIVE VI}

Aunque 'ConvivE' es un concurso académico sus alcances sobrepasan esta dimensión, pues intenta que los estudiantes reflexionen sobre problemas existentes en el ámbito local, especialmente en zonas poco favorecidas. Los temas escogidos tienden a ser de carácter público y no estrictamente académicos, hecho que conlleva a evidenciar problemas reales, así como a afianzar los conocimientos en metodología y técnicas de trabajo para el desarrollo óptimo de proyectos.

Para incentivar el interés de los jóvenes sobre los temas a explorar se programan ciclos de conferencias y visitas a los sitios. De tal modo, se proporciona una visión de la realidad y de las problemáticas que se enfrentan en el proyecto. Hasta la fecha se han efectuado seis ediciones, todas con preocupaciones semejantes. Inicialmente solo participaron estudiantes de Bogotá, para extenderse luego al ámbito nacional y posteriormente al internacional, tras ser invitados países como Venezuela y Ecuador. Todas las descripciones del concurso se basan en el documento base, publicado en

${ }^{5}$ En este apartadoW, todo lo que se encuentra entre comillas y en itálica se obtuvo directamente de tal documento, el cual se referencia en la bibliografía. el website oficial de la Revista Escala (2011) ${ }^{5}$.

La sexta edición del concurso se tituló ConvivE VI: Comunidades indísenas, economía post-minera y urbanismo sostenible: Uribía 2050 . El proyecto se localizó en las proximidades de la frontera con Venezuela, en Uribía (Guajira). Esta región es la "más septentrional del continente suramericano", y donde habita la mayor cantidad de indígenas de Colombia. Además en su territorio se encuentran "las mayores riquezas mineras, con mayor radiación solar y los mejores vientos". El lugar fue seleccionado por su complejidad social, cultural y económica. 
Los principales objetivos de esta edición, según la página oficial del concurso, fueron:

- Proyectar una visión prospectiva multiescalar (vivienda, ranchería, corresimiento, municipio y departamento) y pluriétnica del futuro desarrollo urbano, suburbano y rural de Uribía, teniendo en cuenta que en este convi-
- Plantear una visión del crecimiento municipal que tome como base el Plan de Vida Wayuu y articule armónicamente sobre estos principios las estrategias de desarrollo del Departamento y el Plan Básico de Ordenamiento Territorial, para proyectarse al futuro aprovechando eficientemente los recursos naturales y económicos disponibles, sin poner en riesgo la identidad cultural de base, pues el futuro puede ser construido a partir del reconocimiento de la riqueza cultural, prácticas espaciales y técnicas tradicionales.

- Garantizar un reconocimiento de las dinámicas existentes en el territorio: dinamismo de la economía extractiva pero bajo nivel de ejecución de regalías, alto potencial para las energías renovables pero presencia de pobreza energética, oportunidades para la agricultura pero altos índices de inseguridad alimentaria, PIB por encima del promedio nacional pero altas tasas de analfabetismo y baja cobertura de saneamiento básico, tendencia a la urbanización pero comunidades indízenas seminómadas, dinámicas comerciales tradicionales pero conflictos fronterizos intra e internacionales, entre otras.

- Detallar proyectos específicos de: mejoramiento, provisión y dotación de espacios públicos, equipamientos urbanos, suburbanos, rurales y/o móviles, diseño y mejoramiento de unidades de vivienda (o partes de la misma) existente y nueva; que tipifiquen un modo de intervenir el territorio de manera tal que puedan ser replicables.

En las bases del concurso publicadas por la Revista Escala se describen con más detalle los aspectos relevantes para la elaboración del proyecto. Los países participantes en esta edición fueron Colombia, Venezuela y Ecuador. 
- Su Decana es la Arq. María Leonor Mesa y el Director del Programa de Arquitectura el Arq. Edilberto Molina.

${ }^{7}$ Los profesores que se dedicaron a los proyectos fueron los arquitectos Weymar Mendivelso, del Taller 8, y Edwin Sainea, del Taller 9.

${ }^{8}$ Grupo constituido por: Javier López, Nilson Restrepo, Claudia Castillo, Jorge Murcia y Nelson Velásquez.

\section{Los proyectos}

ConvivE VI, como se ha descrito, envuelve temáticas relativas a, diseño urbano, desarrollo y diseño de vivienda. La Facultad de Arquitectura y de Bellas Artes de la Universidad de Boyacá (con sede en Tunja) ${ }^{6}$ ha participado en varias ediciones del concurso. La estructura curricular de su programa de Arquitectura se divide en ocho áreas: Teoría e Historia de la Arquitectura y la Ciudad; Tecnología; Expresión y Representación Gráfica; Ejercicio Profesional; Investigación; Humanística; materias electivas y el área de Proyectación. En esta última se proponen soluciones proyectuales dirigidas a la construcción del hábitat. Está dividida en 10 talleres, cada uno correspondiente a un semestre. Los talleres de octavo semestre (Diseño de Vivienda Social) y noveno (Diseño de Intervención Urbana Integral), tratan temas de desarrollo y diseño de vivienda, como también de desarrollo y diseño urbano, respectivamente. Así, al ser las temáticas abarcadas similares a las del concurso, se decidió que los estudiantes participaran en la sexta edición. Para ejecutar el trabajo se establecieron tres grupos con alumnos de ambos semestres. Cada uno desarrolló un proyecto que contemplara el urbanismo y la vivienda según las exigencias del concurso, bajo la tutoría de los docentes del taller y con el apoyo de la autora. A continuación se resumen los proyectos.

\section{Grupo $1^{8}$}

La propuesta urbana de este grupo se caracterizó por la utilización de las rancherías, puntos clave en Uribía, conjuntamente con las relaciones entre ellas. Se propusieron grandes manchas verdes, tanto de cultivo como de ocio, para generar una transición entre lo urbano y lo rural. A su vez, el desarrollo de la manzana siguió el mismo concepto de composición. Respecto al desarrollo sostenible, se hicieron planes para el aprovechamiento de aguas grises y negras, al igual que un sistema para la producción de gas y el aprovechamiento de los pozos destinados al agua potable. Las vías en este desarrollo fueron esencialmente peatonales, y tuvieron como sistema base de circulación, el "bicitaxi", ya existente en Uribía. 


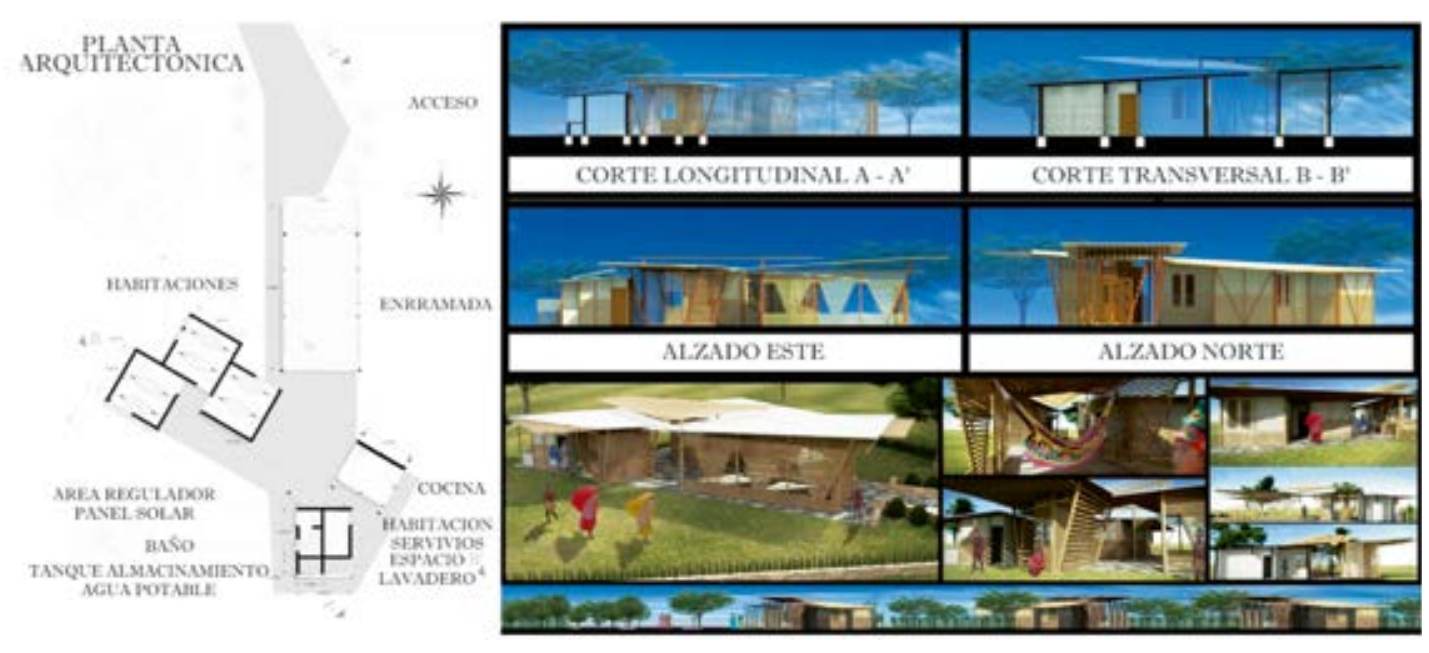

Figura 3. Planta arquitectónica, alzados, cortes y perspectivas de la vivienda del grupo 1. Fuente: Grupo 1

Para la ubicación de la vivienda (figura 3), se tomó como concepto principal la forma de los diseños del tejido Wayuu. También se concibieron espacios públicos en cada manzana para una mejor calidad de vida de los futuros habitantes. Se consideraron las costumbres Wayuu y las de otras poblaciones existentes en Uribía, al tiempo que se plantearon distintos tipos de vivienda para cada grupo. En términos de desarrollo sostenible se buscó aprovechar la energía solar a través de paneles ubicados en las viviendas, al igual que las aguas lluvias para el uso personal. Se propuso el empleo de materiales locales, sin grandes tecnologías y con mecanismos fáciles de producir por los propios Wayuu. El equipamiento previsto fue un centro cultural que siguiera los conceptos de todo el proyecto, cuya función principal es que los habitantes aprovechen el espacio para hacer festivales y otras actividades culturales.

${ }^{9}$ Grupo constituido por: Christian Molina, Ricardo Mojica, Camilo Barrera, Hernán López y Jorge Tarazona.

\section{Grupo $2^{9}$}

En esta propuesta también se aprovecharon las relaciones entre las rancherías y los senderos construidos por los propios Wayuu, así como la jerarquía ya existente de dichos senderos. De otra parte, se planteó una transición entre el área urbana y la rural a través de espacios verdes cruciales. Respecto a la manzana se proyectaron vías esencialmente peatonales y las viviendas se ubicaron cerca de estas para dejar espacios 
centrales verdes, comunes a todas las casas. Esos mismos espacios poseen una red de relaciones peatonales entre ellos, lo que facilita la comunicación libre. En relación con el desarrollo sostenible se contemplaron sistemas de aprovechamiento de aguas residuales y de agua potable.

La vivienda (figura 4) se define formalmente a partir de cuadrados. El detalle más interesante es el uso, en la enramada y en la cocina, de paredes elaboradas con tejido Wayuu y tablas de yotojoro, que representan el telar de los tejidos empleados por los indígenas. Asimismo, se consideran los diferentes tipos poblacionales y sus costumbres. En aras de plantear una vivienda sostenible se incorporan materiales locales, excepto en la cubierta. En referencia a los vientos se crean vacíos y ventanas para la ventilación cruzada, de manera que los espacios interiores se mantengan aireados. El equipamiento es una escuela de artes y cultura Wayuu, ubicada en uno de los centros de la manzana generado por las viviendas.

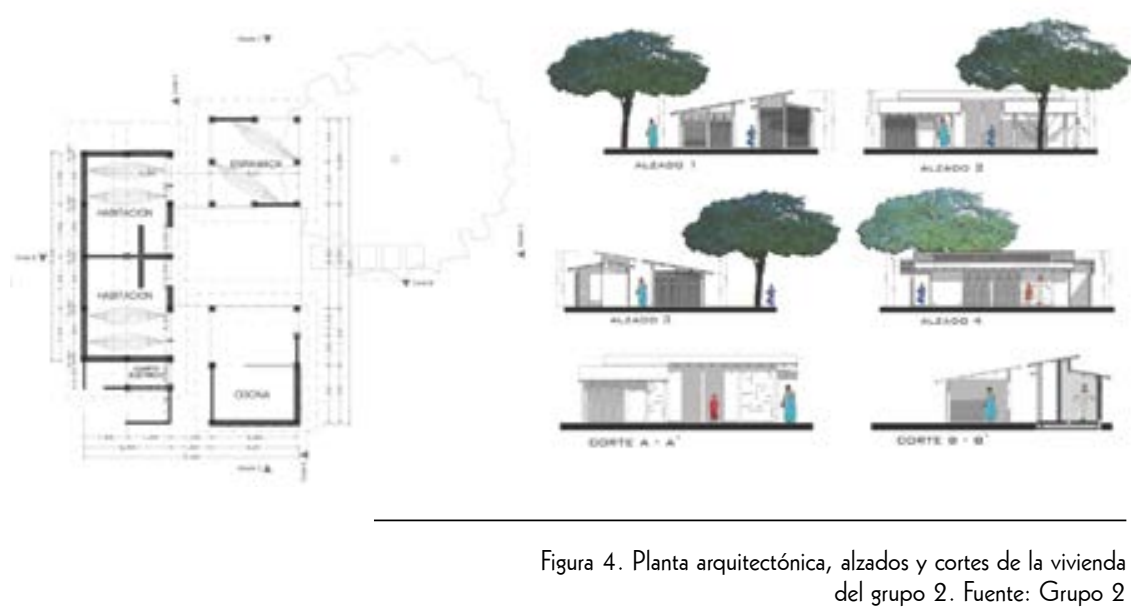

10 Grupo constituido por: Ángela Barrera, Diego García, Juan Carlos Rodríguez, Luis Nieto, Duvan González, Hugo Mesa y Yenny López.

\section{Grupo $3^{10}$}

Esta grupo tuvo en cuenta diversos aspectos (vías, bordes, ambiente, tratamientos, usos, llenos y vacíos) para proponer intervenciones puntuales en el lugar. Se plantearon grandes manchas verdes, surgidas de lo existente, que penetran en toda la 
ciudad y continúan hasta relacionarse con los espacios verdes localizados fuera de ésta. Las formas de dichas manchas se generan a partir de los senderos peatonales construidos, las rancherías, ciertos puntos específicos y los vínculos entre todos estos factores.

El desarrollo de la manzana involucra las vías disponibles, mientras que las viviendas se ubican junto a las vías proyectadas. Igualmente, se deja un espacio central para el humedal artificial, destinado al tratamiento de aguas residuales y a su aprovechamiento para los cultivos comunales, localizados en ese mismo centro de manzana. En este punto también se localiza el espacio público, accesible para los habitantes de las viviendas. Como estrategia de sostenibilidad se concibieron humedales para la recolección y el tratamiento de aguas grises y negras, molinos para el aprovechamiento de agua potable y sistemas de aprovechamiento de energía eólica.

La vivienda (figura 5) tiene formas simples, cuadradas y rectangulares. Se destacan los tejidos Wayuu en todas las fachadas, que funcionan tanto solas (a manera de vano) como en paneles compuestos por tablas de yotojoro, alternadas con dichos tejidos sobre muros de adobe, rodeados por madera de trupillo. Se estudiaron las costumbres de cada tipo poblacional residente en Uribía, de manera que las viviendas se adecuaran a ellos. Para garantizar la sostenibilidad de las casas se propusieron las mismas estrategias que para las manzanas, más la utilización de materiales locales, fáciles de manejar, que optimizaran la construcción. El equipamiento consiste en una central de recolección y almacenamiento de los cultivos producidos en cada manzana, que constructivamente funciona de manera similar a las viviendas.
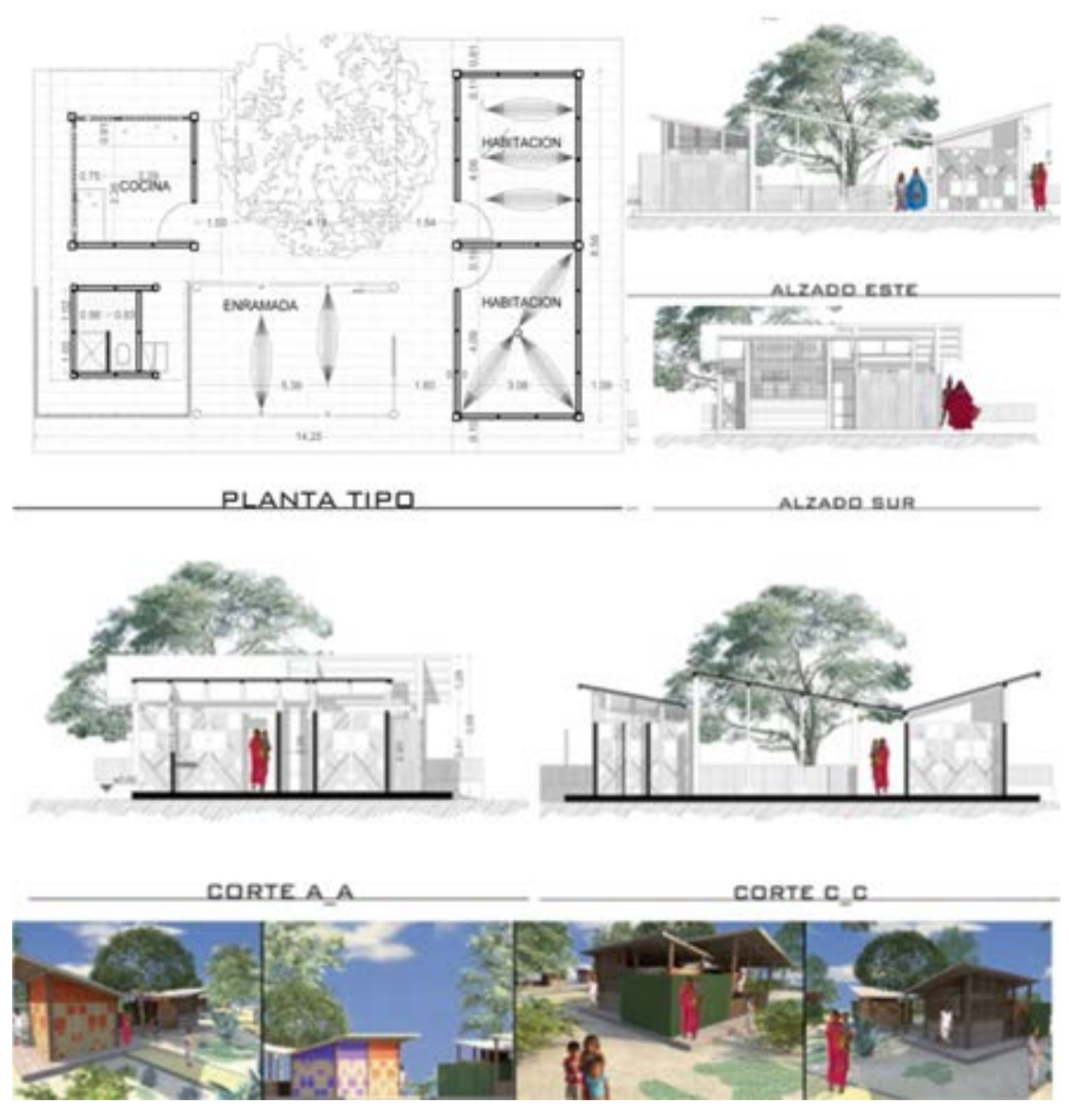

Figura 5. Planta arquitectónica, alzados, cortes y perspectivas de la vivienda del grupo 3 Fuente: Grupo 3 
Para realizar los análisis el primer requerimiento técnico fue el fichero climático de Uribía. Obtenerlo constituyó uno de los principales obstáculos, pues no había disponibilidad del mismo. Para solucionar esta dificultad se estableció comunicación con la empresa generadora del programa Meteonorm $\AA$, el cual es una base de datos climáticos combinada con un generador temporal, que además tiene incorporado un catálogo de datos meteorológicos y procedimientos de cálculos para aplicaciones solares en cualquier lugar del planeta. La empresa proporcionó el fichero, que fue utilizado para los análisis térmicos de los proyectos.

Una vez obtenido el fichero se empezó con la modelación de las viviendas en el Autodesk Ecotect Analisis ${ }^{\circledR}$. Posteriormente, se caracterizó la vivienda con los materiales escogidos por los proyectistas. Los materiales representaron el segundo obstáculo, pues al ser tan específicos y propios del lugar, el programa no contaba con todos los correspondientes. Para resolver este inconveniente se decidió trabajar con materiales similares, existentes en el software. Los no disponibles fueron el yotojoro y el trupillo, dos maderas usadas en la región y propuestas en todos los proyectos. Ya que estas no contaban con características térmicas especiales se adoptaron otros tipos, tales como la caoba para el yotojoro y el roble para el trupillo. Se decidió trabajar con estas maderas en la medida que el trupillo es utilizado para elementos estructurales y el yotojoro para los no estructurales. Una vez caracterizadas las viviendas se hizo una evaluación de su confort térmico y con los resultados obtenidos se propusieron recomendaciones orientadas a mejorar dicho elemento. Después, se cambiaron los materiales y se efectuaron modificaciones en los modelos ya generados, para continuar con nuevos análisis hasta lograr un confort térmico aceptable. Todos los análisis se hicieron para el 21 de julio, día más caliente del año, pues corresponde a la situación más crítica en este clima.

A continuación se describen cada una de las viviendas con los materiales propuestos inicialmente, las evaluaciones aplicadas, las recomendaciones y los análisis finales conducentes a la verificación del confort térmico. 


\section{Proyecto 1}

Los materiales utilizados en la propuesta preliminar pueden apreciarse en la figura 6:

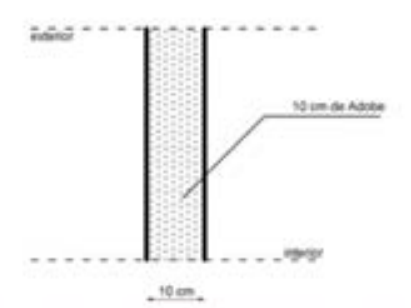

$10 \mathrm{~cm}$ (espesor) de adobe para las paredes de los cuartos y de la cocina.

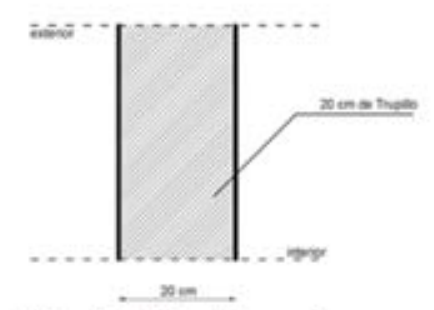

$20 \mathrm{~cm}$ (diámetro) de trupillo para las estructuras de todos los espacios.

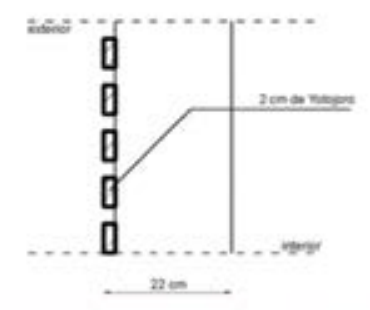

$2 \mathrm{~cm}$ (espesor) de yotojoro en las maderas decorativas de todos los espacios.

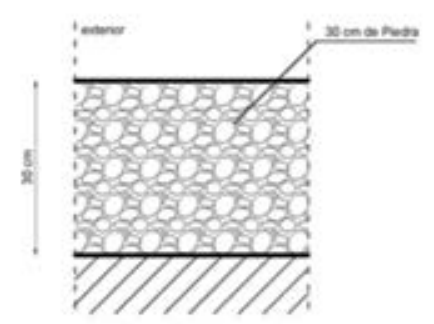

$30 \mathrm{~cm}$ (espesor) de piedra para los pisos.

$4 \mathrm{~cm}$ (espesor) de yotojoro en las puertas de los cuartos y del bafio.

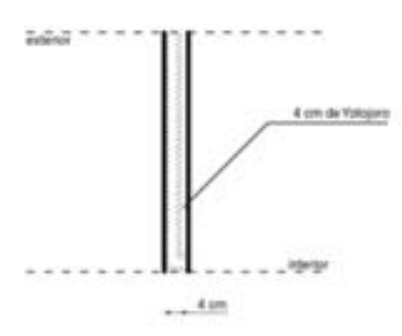

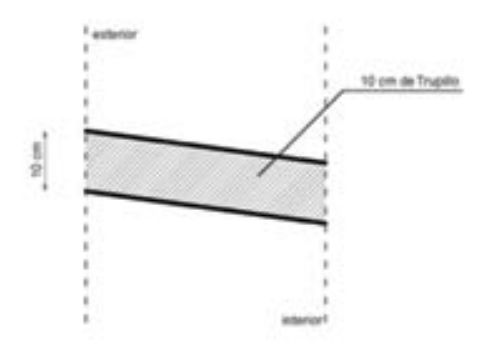

$10 \mathrm{~cm}$ (de espesor) de trupillo para la cubierta.

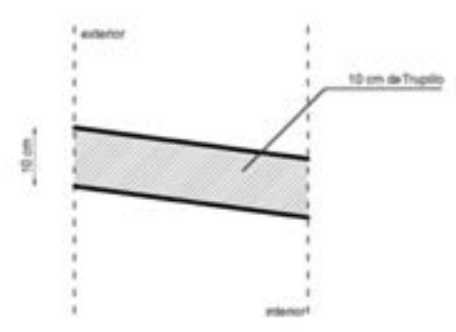

$10 \mathrm{~cm}$ (espesor) de trupillo en las maderas de la pérgola, en el centro de la vivienda.
Figura 6. Detalles y materiales del proyecto del grupo 1. Fuente: Integrantes Grupo 1

Con estos materiales se hizo el análisis del confort térmico, del que se obtuvieron como resultado los gráficos 7 y 8 , los cuales denotan el poco confort de este tipo en los espacios de la vivienda. 


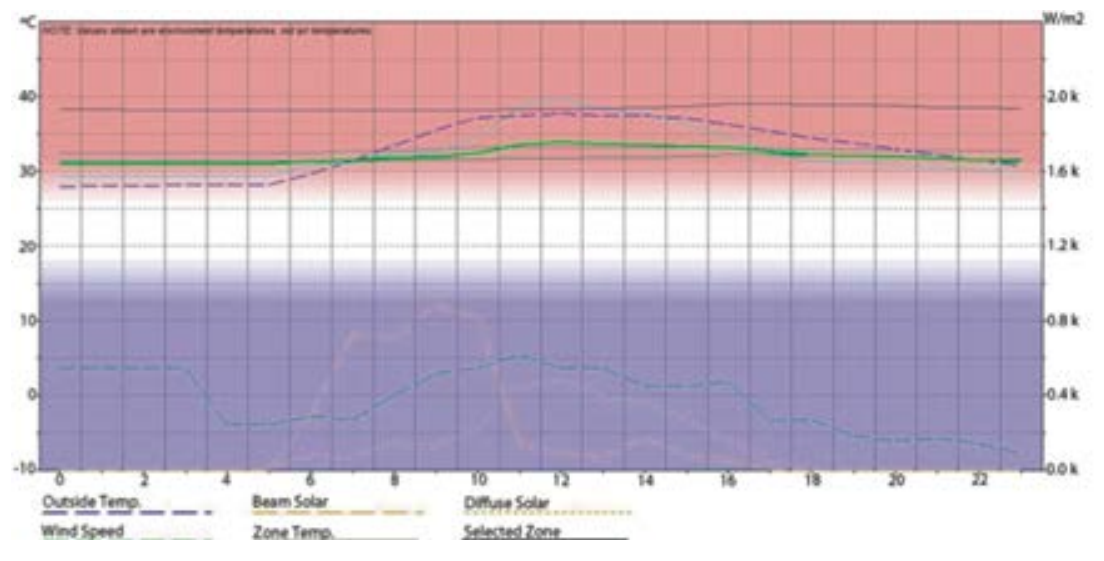

Figura 8. Análisis de las temperaturas a lo largo del día de la vivienda del grupo 1 en el programa Autodesk Ecotect Analysis $®$, para el día 21 de julio, en Uribía (en negro se evidencian los cuartos de la vivienda). Fuente: Autora

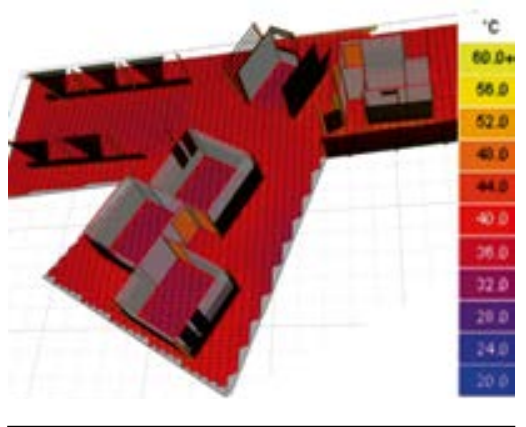

Figura 7. Análisis del confort térmico de la vivienda del grupo 1 en el programa Autodesk Ecotect Analysis ${ }$ para el día 21 de julio, en Uribía.. Fuente: Autora

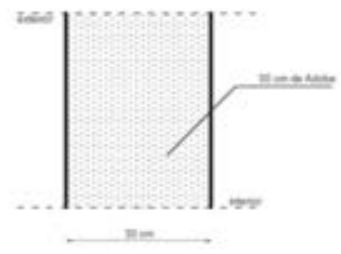

Aumentar el espesor de las paredes de adobe de $10 \mathrm{~cm}$ para $30 \mathrm{~cm}$.

Mejorar la ubicación de los árboles, para mejorar el confort cerca de la vivienda e mismo dentro de los espacios.
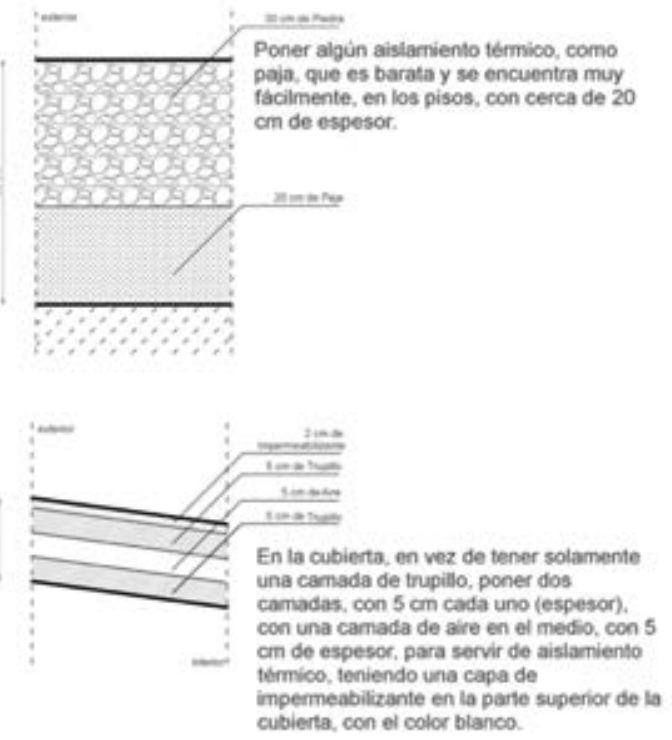

Figura 9. Detalles y materiales del proyecto del grupo 1 después de las modificaciones Fuente: Autora 


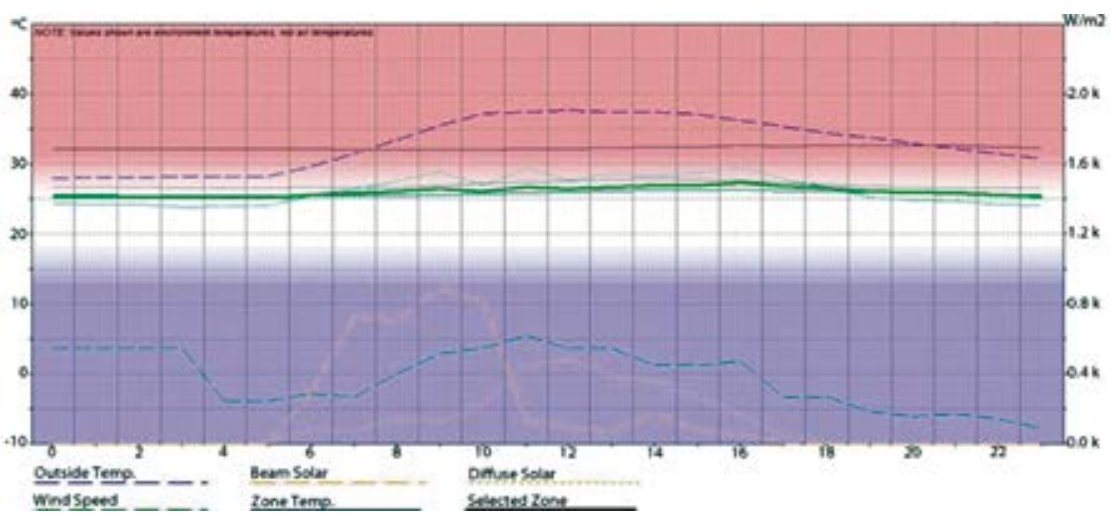

Tras los cambios se practicaron nuevos análisis, representados en las figuras 10 y 11 , en las que se observa la diferencia de temperaturas en el interior con relación al análisis previo. Se . denota un confort térmico constante a lo largo del día dentro de las habitaciones, espacios que necesitan mayor confort. Las otras áreas carecen de ese comportamiento constante, pues no poseen tanta masa térmica como las habitaciones, pero sus temperaturas no se encuentran por encima de las de confort. Si se considera que se trata de espacios abiertos casi en su totalidad, las alteraciones no resultan significativas. En cuanto a ventilación y sombreado no fue necesario incorporar modificaciones, ya que al diseñar el edificio se tuvieron en cuenta esos dos factores.

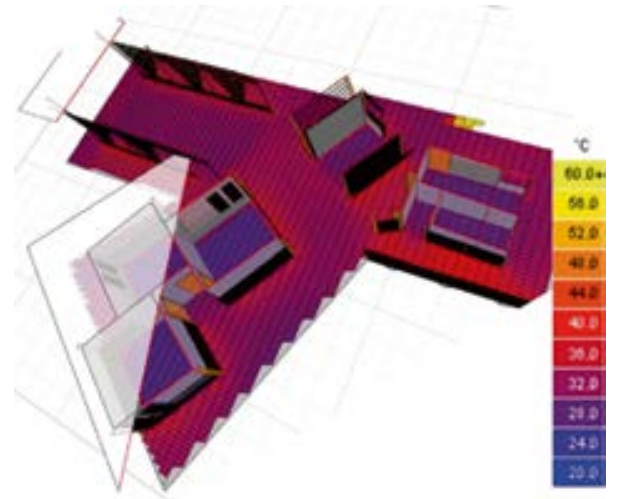

Figura 10. Análisis de las temperaturas a lo largo del día de la vivienda del grupo 1 en el programa Autodesk Ecotect Analysis $®$, para el día 21 de julio, en Uribía (se evidencian en negro los cuartos de la vivienda). Fuente: Autora

Figura 11. Análisis del confort térmico de la vivienda del grupo 1 en el programa Autodesk Ecotect Analysis ${ }^{\circledR}$ para el día 21 de julio, en Uribía. Fuente: Autora

\section{Grupo 2}

Los materiales utilizados preliminarmente por el grupo 2 se describen en la Figura

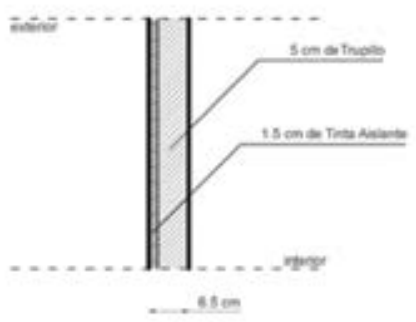

$5 \mathrm{~cm}$ (espesor) de trupillo con tinta aislante para las paredes de los cuartos y de la cocina.

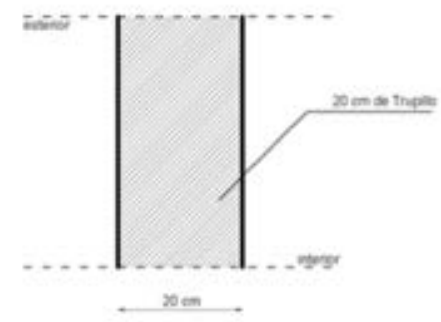

$20 \mathrm{~cm}$ (diàmetro) de trupillo para las estructuras de todos los espacios 


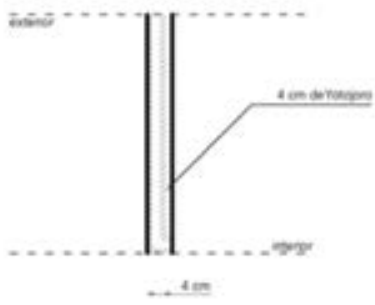

$4 \mathrm{~cm}$ (espesor) de yotojoro en las puertas de los cuartos y del baño

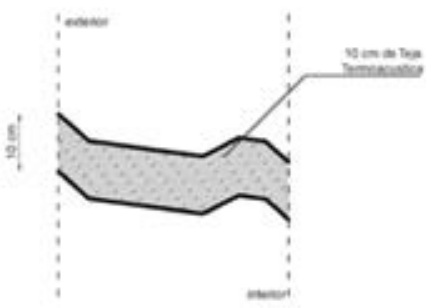

$10 \mathrm{~cm}$ (de espesor) de tejas termoacústicas para la cubierta.

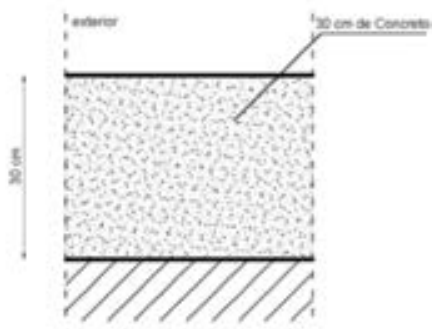

$30 \mathrm{~cm}$ (espesor) de concreto para los pisos.

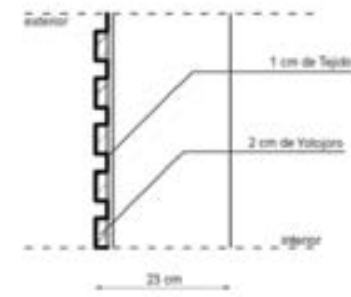

$2 \mathrm{~cm}$ (espesor) de yotojoro en las maderas decorativas de todos los espacios y $1 \mathrm{~cm}$ (espesor) de tejido wayuu en las partes decorativas con el yotojoro.

Figura 12. Detalles y materiales del proyecto del grupo 2. Fuente: Autora
12. Con estos materiales se hizo el análisis del confort térmico, cuyo resultado puede visualizarse en los gráficos 13 y 14 . En estos se denota el poco confort térmico en los espacios de la vivienda y las altísimas temperaturas predominantes.
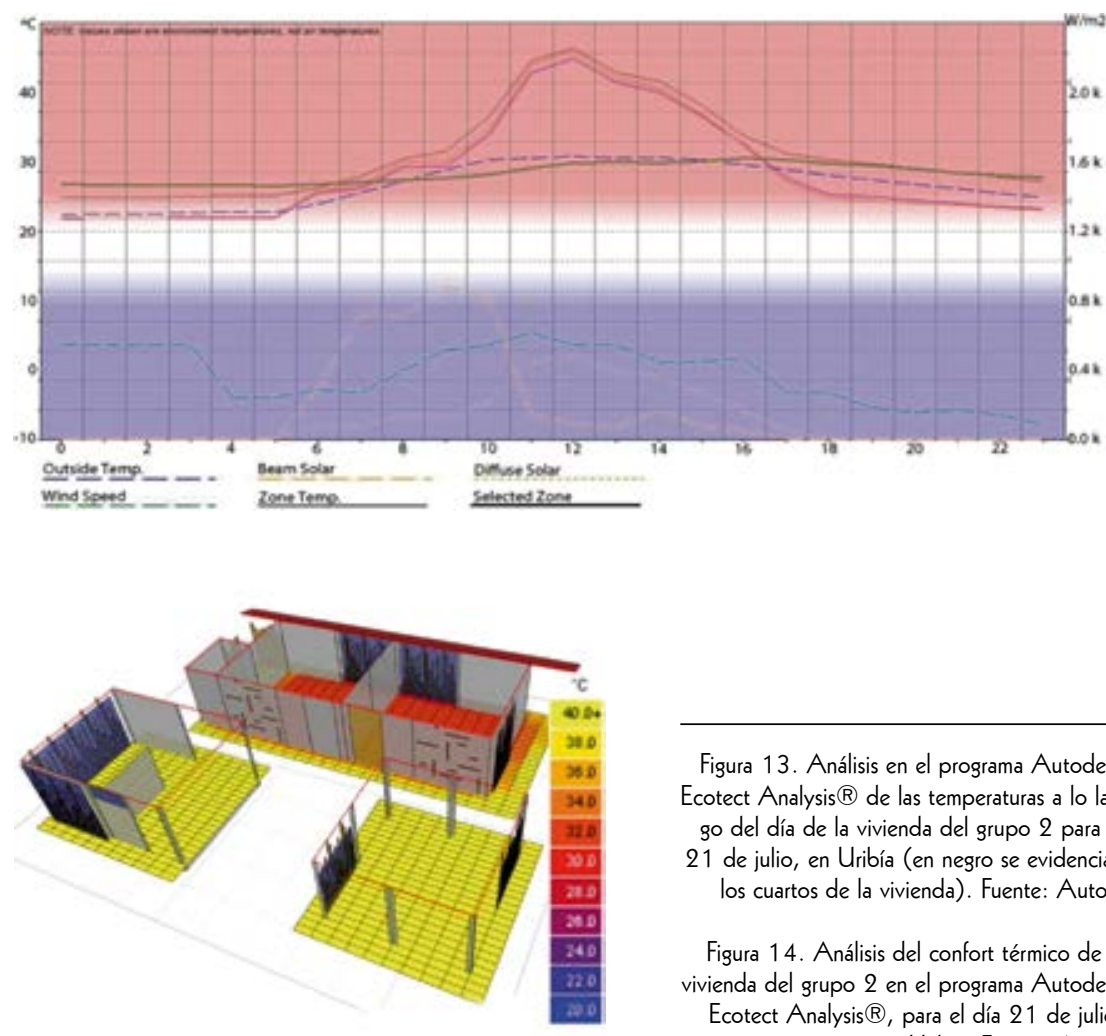

Después de estos análisis se efectuaron algunos cambios en los materiales para mejorar el confort térmico dentro de los espacios, tal como se verifica en la figura 15. 


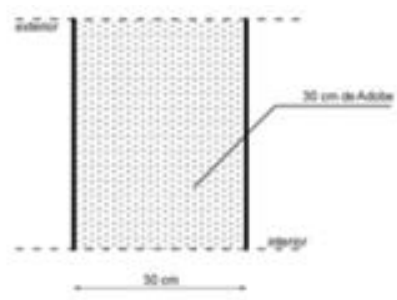

Cambiar el material de las paredes de trupillo para adobe (con $30 \mathrm{~cm}$ de espesor) para tener masa térmica.

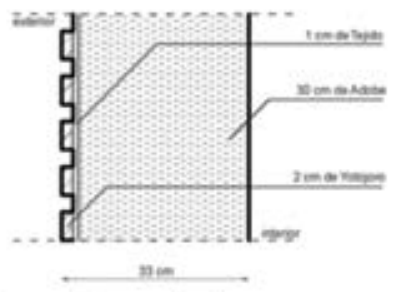

Poner las paredes que tenian como constitución el tejido y las tablas de yotojoro , en los cuartos y la cocina, como

solamente decorativas, teniendo como base las paredes de adobe.

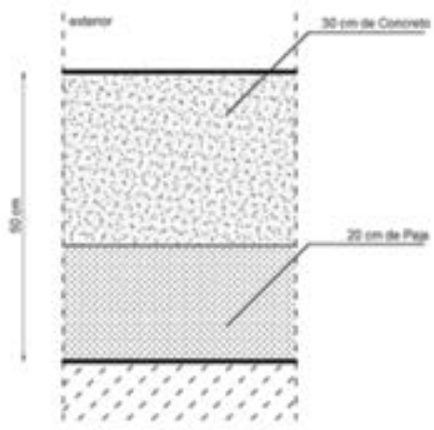

Poner algún aislamiento térmico, como paja, que es barata y se encuentra muy facilmente, en los pisos, con cerca de 20 $\mathrm{cm}$ de espesor.

Cerrar el espacio entre las dos cubiertas de los cuartos con una pared de trupillo, con $5 \mathrm{~cm}$ de espesor, pero con 4 huecos de $20 \times 20 \mathrm{~cm}$, para continuar a ventilar, pero sin que el calor entre tan fácilmente para el interior de los cuartos.

Figura 15. Detalles y materiales, después de las modificaciones, del proyecto del grupo 2 Fuente: Autora
Tras los cambios en los materiales se practicaron nuevos análisis, representados en las figuras 16 y 17 , en las que puede verse la diferencia de temperaturas en el interior en relación con el análisis anterior. En este caso, como sucedió en el proyecto previo, también se observa un buen confort térmico dentro de las habitaciones, las zonas que más lo necesitan, las cuales presentan un comportamiento térmico constante a lo largo del día. Los otros espacios, aunque no ofrecen esa constancia, tampoco tienen temperaturas por encima de las de confort. En cuanto al sombreado no fue necesario hacer modificaciones, pues en el diseño se tuvo en cuenta este factor.
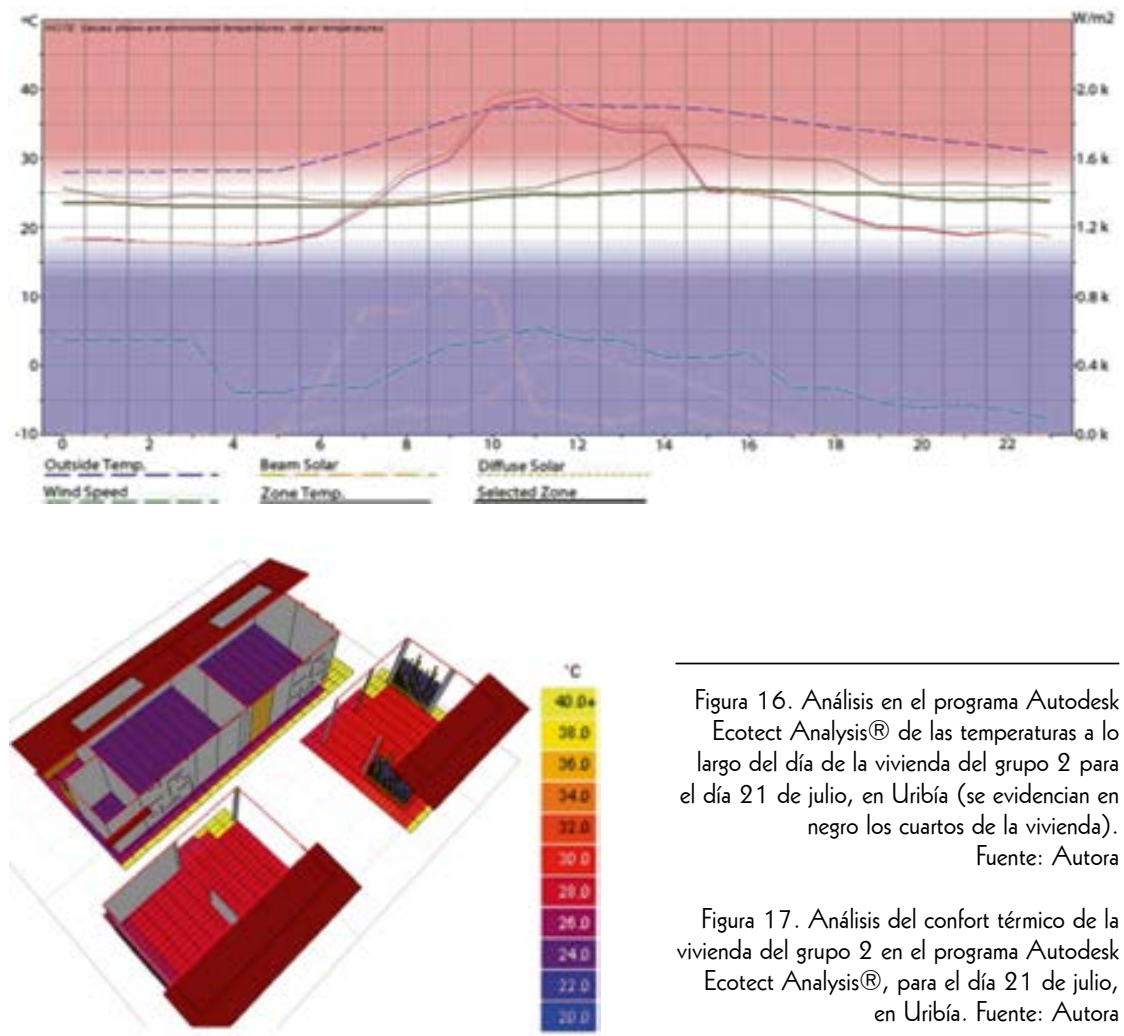

Figura 16. Análisis en el programa Autodesk Ecotect Analysis ${ }^{\circledR}$ de las temperaturas a lo largo del día de la vivienda del grupo 2 para el día 21 de julio, en Uribía (se evidencian en negro los cuartos de la vivienda).

Fuente: Autora

Figura 17. Análisis del confort térmico de la vivienda del grupo 2 en el programa Autodesk

Ecotect Analysis ${ }^{\circledR}$, para el día 21 de julio, en Uribía. Fuente: Autora 


\section{Grupo 3}

Los materiales utilizados por el grupo 3 se presentan en la figura 18 .

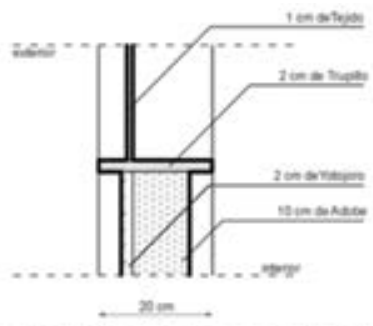

Paneles que tenian varias partes diferentes como constitución, aplicados en los cuartos. cocina y baños:

Partes solamente con tejido wayuu con $1 \mathrm{~cm}$ de espesor, sirviendo de ventanas:

Partes con yotojoro en el exterior con $2 \mathrm{~cm}$ de espesor y en el interior con $10 \mathrm{~cm}$ de espesor de adobe:

Divisiones y envolvente de las partes descritas en trupillo, con $20 \mathrm{~cm}$ de largo y 2 de espesor;

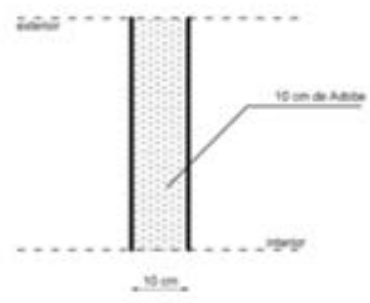

$10 \mathrm{~cm}$ (espesor) de adobe en las paredes de la cocina.

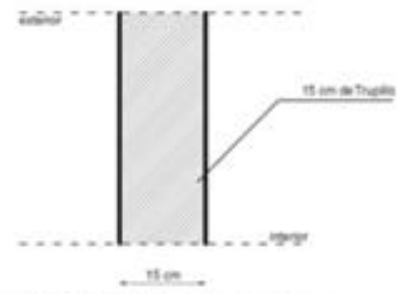

$15 \mathrm{~cm}$ (diámetro) de trupillo para las estructuras de todos los espacios y las paredes de la enramada.

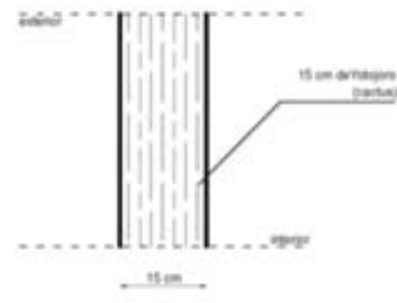

$15 \mathrm{~cm}$ (diámetro) del cactus originario del yotojoro en las paredes que rodean los baños.

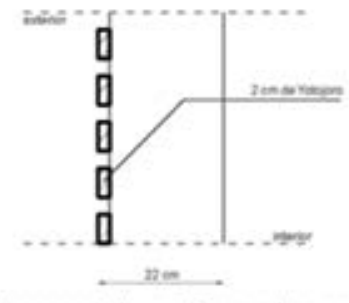

$2 \mathrm{~cm}$ (espesor) de yotojoro en las maderas decorativas de la cocina.

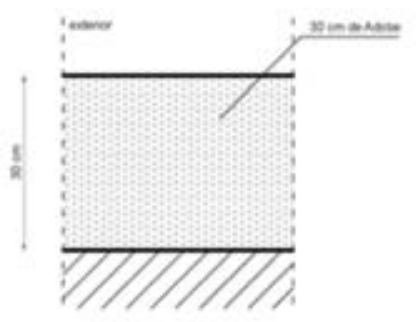

$30 \mathrm{~cm}$ (espesor) de adobe para los pisos.
$10 \mathrm{~cm}$ (de espesor) de tierra para la

cubierta.

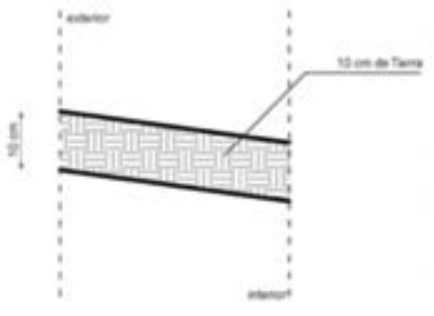

Figura 18. Detalles y materiales del proyecto del grupo 3. Fuente:Autora 
Con estos materiales se hizo el análisis del confort térmico, cuyos resultados -." - se ven en los gráficos 19 y 20 , en los que se denota el poco confort térmico en los espacios de la vivienda.

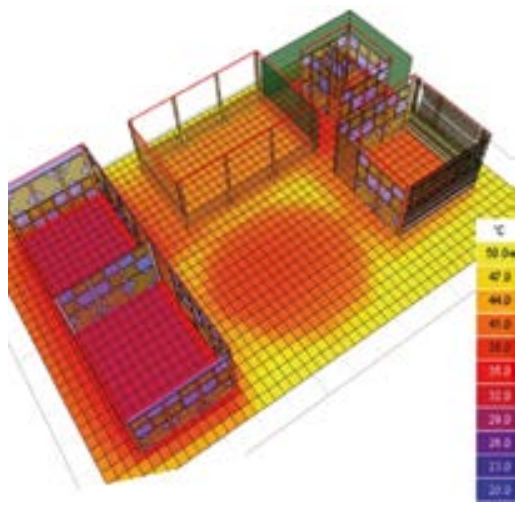

Figura 19. Análisis del confort térmico de la vivienda del grupo 3 en el programa Autodesk Ecotect Analysis ${ }^{\circledR}$, para el 21 de julio, en Uribía. Fuente. Autora

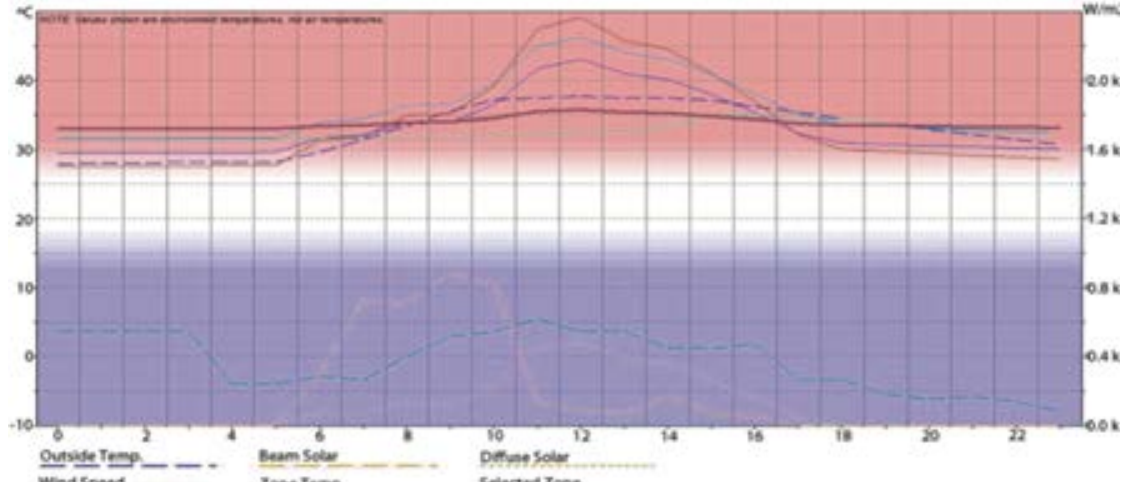

Figura 20. Análisis en el programa Autodesk Ecotect Analysis ${ }^{\circledR}$, de las temperaturas a lo largo del día de la vivienda del grupo 2 para el 21 de julio, en Uribía (se evidencian en negro los cuartos de la vivienda). Fuente. Autora

Después de estos análisis se realizaron cambios en los materiales con el fin de mejorar el confort térmico dentro de los espacios de la vivienda, como se verifica en la figura 21:

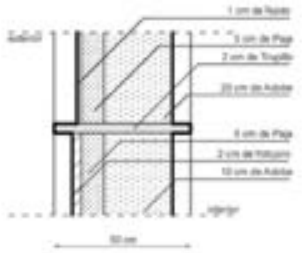

Canbiarlos paneles:

Las partes que solo tenian tejido. pasan a tener el tejido. $5 \mathrm{~cm}$ (espeson) de paja (que sirve de aislante termico) y $20 \mathrm{~cm}$ (espeson) de adobe, para oblener mayor masa termica, dejando solamente 2 as 5 huecos por fachada, para tener ventilación; Las partes de yotojoro. pasan a tener tambiens $5 \mathrm{~cm}$ (espeson) de y $20 \mathrm{~cm}$ (espesor) de adobe, por las misme razones det punto anterior.

Las divisiones y envolvente pasan a tener $30 \mathrm{~cm}$ de fargo, continuando con los 2 $\mathrm{cm}$ de espesor.

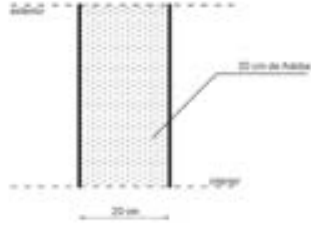

Aumentar el espesor de las paredes de ta cocina de $10 \mathrm{~cm}$ para $20 \mathrm{~cm}$ de espesori 


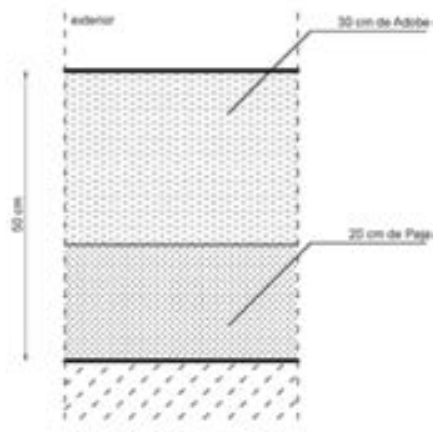

Poner algún aislamiento térmico, como paja, que es barata y se encuentra muy fácilmente, en los pisos, con cerca de 20 $\mathrm{cm}$ de espesor.

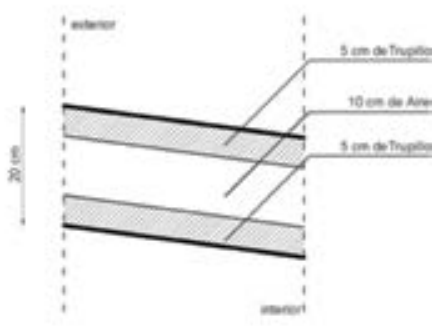

Cambiar la estructura y materiales de la cubierta, pasando a tener 2 camadas de trupillo de $5 \mathrm{~cm}$ de espesor con una camada de aire en el medio con $10 \mathrm{~cm}$ de espesor, para garantir algún aislamiento térmico por parte de la cubierta.

Figura 21. Detalles y materiales del proyecto del grupo 3 después de las modificaciones. Fuente: Autora
Después de los cambios en los materiales se hicieron nuevos análisis, representados en las figuras 22 y 23 , en los que puede observarse la diferencia en las temperaturas en el interior. En este caso también se denota un confort térmico constante a lo largo del día dentro de los cuartos. Si se tiene en cuenta que los demás espacios son casi completamente abiertos, las pequeñas alteraciones térmicas no son significativas. El diseño del proyecto consideró el sombreado, por lo que no fue necesario hacer modificaciones en este sentido. Finalmente, se puede concluir que el análisis del confort térmico es
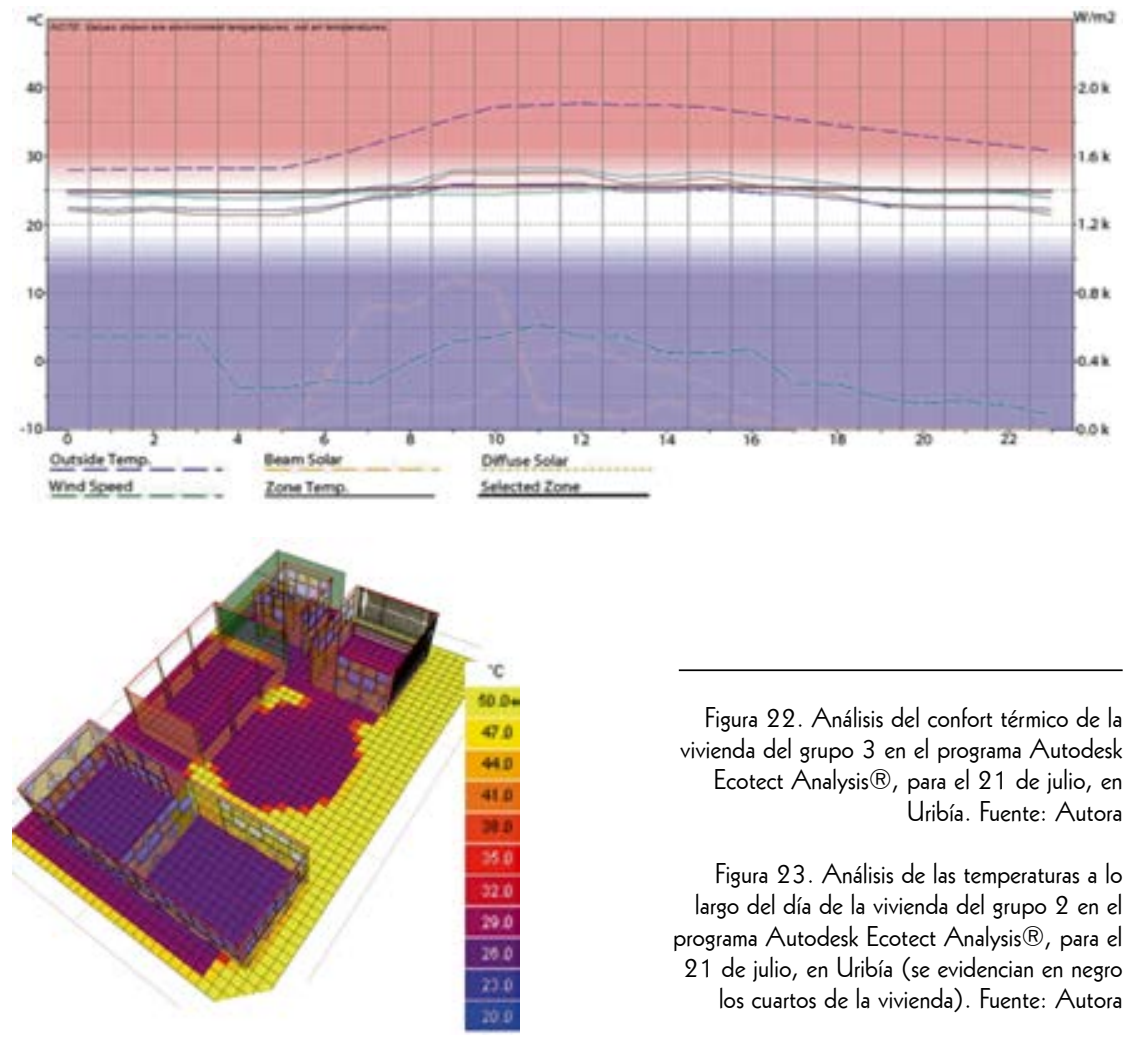

Figura 22. Análisis del confort térmico de la vivienda del grupo 3 en el programa Autodesk

Ecotect Analysis ${ }^{\circledR}$, para el 21 de julio, en Uribía. Fuente: Autora

Figura 23. Análisis de las temperaturas a lo largo del día de la vivienda del grupo 2 en el programa Autodesk Ecotect Analysis ${ }^{\circledR}$, para el

21 de julio, en Uribía (se evidencian en negro los cuartos de la vivienda). Fuente: Autora

indispensable en los proyectos arquitectónicos, especialmente en aquellos emplazados en climas extremos como el de Uribía. También es importante señalar que conocer y adaptar los materiales a las condiciones climáticas es un factor de incidencia en la calidad de vida de los usuarios finales de los espacios proyectados. El soporte brindado por los programas de análisis es fundamental en la concreción de proyectos coherentes y sostenibles, por lo que constituyen una valiosa herramienta para el arquitecto. 


\section{CONCLUSIONES}

Existen diversos programas de simulación que ofrecen herramientas importantes a los arquitectos para mejorar el diseño. Estos programas se adaptan a otros de dibujo, de manera que son un complemento muy eficiente al momento de diseñar.

Concursos como ConvivE proponen la realización de ejercicios académicos con problemáticas, preocupaciones e intenciones ligadas a contextos particulares. Por lo tanto, la participación en ellos permite a los estudiantes de arquitectura tener contacto directo con situaciones que se viven en comunidades con serios problemas de habitabilidad.

La sostenibilidad debe ser entendida como un requisito fundamental de los proyectos. Es consecuente pensar que está ligada a los materiales, al emplazamiento y a las acciones sencillas relacionadas con la coherencia del proyecto con su entorno y sus necesidades.

En las propuestas presentadas al concurso se verificó que mediante cambios relativamente sencillos se logra una mejoría en el confort térmico. En este sentido, los programas de simulación de dicho confort en los edificios constituyen una valiosa herramienta que apoya a los arquitectos en la toma de decisiones para garantizar proyectos eficientes, sin que esto implique cambios sustanciales en los materiales.

Durante el apoyo a los proyectos que se presentaron al concurso se constató que el hecho de incorporar materiales autóctonos, condiciones climáticas específicas y factores culturales, resulta vital para ofrecer a la comunidad espacios amables y coherentes con los contextos. 
Crawley, D. B., Hand, J. W., Kummert, M. \& Griffith, B. T. (2005). Contrasting The Capabilities of Building Energy Performance Simulation Programs. Washington, USA: U.S. Department of Energy.

Mills, E. (2004). Inter-comparison of North American residential energy analysis tools. Energy and Buildings, 36, 865-880.

REFERENCIAS

Natural Frequency. (2011). Archived Ecotect Resources - Community Wiki. Recuperado el 15 de ene. de 2011, de http://wiki.naturalfrequency.com

Revista Escala. (2011). Bases definitivas del Concurso internacional universitario de hábitat ConvivE VI - Comunidades indísenas, economía post-minera y urbanismo sostenible: Uribía 2050. Recuperado el 20 de sept. de 2011, de http:// www.revistaescala.com/index.php? lteming $=139$

U.S. Department of Energy. (2011). Building Energy Software Tools Directory. Recuperado el 1 de oct. de 2011, de http://apps1 .eere.energy.gov/buildings/ tools_directory/subjects.cfm/pagename $=$ subjects/pagename_menu $=$ whole building_analysis/pagename_submenu $=e$

Zimmerman, D. R. (2003). Sustainable Architecture Guideline. Recuperado el 25 de sept. de 2011, de http://www.tva.com/abouttva/energy_management/documents/sustainable_guideline_8.pdf 